\title{
HUBUNGAN DUKUNGAN KELUARGA DENGAN KEPATUHAN DIET PADA PENDERITA HIPERTENSI DI WILAYAH KERJA PUSKESMAS PANCUR KABUPATEN LINGGA TAHUN 2020
}

Nilam Sari, Mira Agusthia, Rachmawaty M Noer

STIKes Awal Bros Batam Indonesia

Email: nilam22sari08@gmail.com, agusthiamira@gmail.com, rachmawatymnoer1977@gmail.com

\begin{tabular}{|c|c|}
\hline INFO ARTIKEL & ABSTRAK \\
\hline $\begin{array}{l}\text { Tanggal diterima: } 2 \text { Oktober } 2020 \\
\text { Tanggal revisi: } 10 \text { Oktober } 2020 \\
\text { Tanggal yang diterima: } 25 \\
\text { Oktober } 2020 \\
\text { Kata kunci: } \\
\text { Hipertensi; dukungan keluarga; } \\
\text { kepatuhan diet hipertensi }\end{array}$ & $\begin{array}{l}\text { Tujuan Penelitian untuk mengetahui hubungan } \\
\text { dukungan keluarga dengan kepatuhan diet penderita } \\
\text { hipertensi di wilayah kerja Puskesmas Pancur } \\
\text { Kabupaten Lingga Tahun"2019?"."Penelitian } \\
\text { menggunakan metode deskriptif korelasi pendekatan } \\
\text { secara cross sectional, pemilihan sampel dengan } \\
\text { tekhikpurposive sampling, jumlah sampel } 55 \\
\text { responden. Hasil penelitian diuji dengan uji Spearman } \\
\text { Rho dengan derajat kemaknaan } \alpha=0,00 \text {, diperoleh } \\
\text { hasil p=0,000 dimana (p } \leq 0,05) \text {, dengan kekuatan } \\
\text { (r=0,851) yaitu sangat kuat dan arah hubungan } \\
\text { positif artinya koefisien korelasi adalah signifikan, } \\
\text { berarti"ada Hubungan Dukungan Keluarga Dengan } \\
\text { Kepatuhan Diet Pada Penderita Hipertensi Di } \\
\text { Wilayah Kerja Puskesmas Pancur Kabupaten } \\
\text { Lingga"Tahun 2019. Diharapkan agar perawat dapat } \\
\text { memberikan bimbingan pelayanan kesehatan bagi } \\
\text { pasien hipertensi untuk dapat menyadari pentingnya } \\
\text { kepatuhan diet hipertensi dan membantu keluarga agar } \\
\text { memberi dukungan keluarga untuk membantu } \\
\text { pasien mengotrol diet hipertensi }\end{array}$ \\
\hline
\end{tabular}

\section{Pendahuluan}

Hipertensi yaitu "suatu kondisi yang ditandai dengan adanya peningkatan tekanan darah sistolik lebih dari 140 $\mathrm{mmHg}$ dan tekanan darah diastolik lebih dari $90 \mathrm{mmHg}$ pada dua kali pengukuran dalam keadaan cukup istirahat atau tenang" (Pusat Data dan Informasi Kemenkes RI, 2014). (Runtukahu, 2015) di dalam penelitiannya juga menyebutkan bahwa hipertensi adalah "peningkatan tekanan darah seseorang di atas $120 / 80 \mathrm{mmHg}$ yang merupakan salah satu penyebab utama penyakit jantung, stroke dan gagal ginjal". Faktor-faktor lain yang bisa dimasukan dalam daftar penyebab hipertensi ialah lingkungan, kelainan metabolisme intra seluler, serta faktor-faktor yang meningkatkan risikonya misalnya obesitas, konsumsi alkohol, merokok serta kelainan darah (Muchid et al., 2006). Hipertensi dikenal secara luas sebagai penyakit kardiovaskular, dikarenakan merupakan salah satu resiko utama penyebab gangguan jantung, dan diperkirakan telah menyebabkan $4,5 \%$ dari beban penyakit secara global, dan prevalensinya hampir sama besar di negara berkembang maupun di negara maju (Huda et al., 2020). Keberhasilan pengobatan hipertensi salah satunya dipengaruhi oleh kepatuhan melaksanakan diet. Melaksanakan pola hidup sehat telah banyak terbukti dapat menurunkan tekanan darah serta dapat 
mencegah terjadinya penyakit kardiovaskuler (Soenarta, 2015).

"Penderita hipertensi harus patuh dalam menjalankan diet hipertensi setiap hari, agar keadaan tekanan darah penderita hipertensi tetap stabil sehingga dapat terhindar dari penyakit hipertensi dan komplikasinya" (Agrina, 2013). "Upaya pencegahan dan penanggulangan hipertensi melalui pola makan sangat penting bagi penderita hipertensi. Hipertensi menyebabkan setidaknya $45 \%$ kematian akibat penyakit jantung dan 51\% kematian akibat stroke (Bertalina \& Muliani, 2016). Hipertensi terbukti sering muncul tanpa gejala, namun penyakit hipertensi ini baru disadari oleh mereka setelah terjadi komplikasi (Rahmayani, 2019). Pengaturan diet pada penderita hipertensi dan keteraturan pemeriksaan tekanan darah akan berhasil apabila pasien patuh. Kepatuhan merupakan tingkat seseorang dalam melaksanakan aturan-aturan perilaku yang disarankan". Tujuan diet adalah "membantu menurunkan tekanan darah tinggi serta mampu mengurangi atau menghilangkan penimbunan garam atau air dalam jaringan tubuh" (Sustrani, 2015). Dengan dukungan keluarga dalam diet hipetensi membantu menurunkan hipertensi pada penderita hipertensi. "Dukungan keluarga yang diberikan pada penderita hipertensi meliputi dukungan informasi, finansial, dukungan emosional dan dukungan penilaian atau penghargaan". Penelitian lain yang dilakukan oleh (Rosyid \& Effendy, 2016) menunjukkan bahwa "rendahnya angka kepatuhan terhadap diet rendah garam membuat meningkatnya angka kejadian hipertensi". (Lindner, Menzies, Kelly,Taylor, 2013) menjelaskan "pemberian intervensi merupakan faktor penting dalam perubahan sikap kepatuhan dalam pengobatan penyakit kronik seperti perubahan sikap dalam kepatuhan minum obat, kepatuhan aktivitas sehari-hari dan kepatuhan melaksanakan diet".

Studi pendahuluan yang dilakukan peneliti terhadap 10 orang pasien yang melakukan kunjungan ke Puskesmas Pancur pada tanggal 10 November 2019-11 November 2019 diperoleh data bahwa sebanyak 5 orang pasien dengan hipertensi tinggal bersama dengan anak dan dalam pengawasan kontrol gizi mengatakan bahwa tekanan darah dapat terkontrol dan tidak mengalami kenaikan yang signifikan. Sebanyak 4 orang pasien dengan hipertensi yang tidak dalam pengawasan keluarga terhadap diet gizi mengaku kurang mematuhi diet hipertensi sehingga hipertensi tidak terkontrol. Sebanyak 1 orang pasien dengan hipertensi yang tidak dalam pengawasan keluarga terhadap diet gizi namun sering mengikuti pertemuan posyandu lansia mengaku menyadari perlunya kepatuhan terhadap diet gizi dan mengatakan bahwa hipertensi dapat terkontrol.

Tujuan penelitian untuk mengetahui Hubungan Dukungan Keluarga Dengan Kepatuhan Diet Penderita Hipertensi Di Wilayah Kerja Puskesmas PancurKabupaten Lingga Tahun 2020

\section{Metode Penelitian}

Rancangan penelitian ini adalah deskriptif korelasional dengan metode cross sectional yaitu rancangan penelitian dengan melakukan pengukuran atau pengamatan pada saat bersamaan atau sekali waktu. Penelitian ini dilakukan untuk mengetahui tentang "Hubungan Dukungan Keluarga Dengan Kepatuhan Diet Penderita Hipertensi Di Wilayah Kerja Puskesmas Pancur Kabupaten Lingga Tahun 2019”, kemudian dilakukan analisis untuk mencari ada tidaknya Hubungan Dukungan 
Keluarga Dengan Kepatuhan Diet Pada Penderita Hipertensi Di Wilayah Kerja Puskesmas Pancur Kabupaten Lingga Tahun 2020. Pemilihan sampel dengan tekhik purposive sampling, jumlah sampel 55 responden.

\section{Hasil dan Pembahasan}

\section{Analisa Univariat}

a. Distribusi frekuensi berdasarkan karakteristik responden.

Tabel 1

Distribusi Frekuensi Karakteristik Usia, Jenis Kelamin, Status perkawinan, Pendidikan, dan Tempat Tinggal Responden Penderita Hipertensi Di Wilayah Kerja Puskesmas Pancur Kabupaten Lingga Tahun 2020"

\begin{tabular}{|c|c|c|c|}
\hline No & Karakteristik & Frekuensi (f) & Persentase (\%) \\
\hline \multirow[t]{6}{*}{1} & Usia & & \\
\hline & a. $30-40$ tahun & 2 & 3,64 \\
\hline & b. $41-50$ tahun & 9 & 16,36 \\
\hline & c. 51-60 tahun & 29 & 52,73 \\
\hline & d. $\quad 61-70$ tahun & 10 & 18,18 \\
\hline & e. $>70$ tahun & 5 & 9,09 \\
\hline \multirow[t]{3}{*}{2} & Jenis kelamin & & \\
\hline & a. Laki laki & 21 & 38,18 \\
\hline & b. Perempuan & 34 & 61,82 \\
\hline \multirow[t]{4}{*}{3} & Status perkawinan & & \\
\hline & a. Belum Menikah & 3 & 5,46 \\
\hline & b. menikah & 43 & 78,18 \\
\hline & c. Janda/duda & 9 & 16,36 \\
\hline \multirow[t]{5}{*}{3} & Pendidikan & & \\
\hline & a. SD & 12 & 21,82 \\
\hline & b. SMP & 28 & 50,91 \\
\hline & c. SMU/SMK & 9 & 16,36 \\
\hline & d. Perguruan Tinggi & 6 & 10,91 \\
\hline \multirow[t]{6}{*}{4} & Tempat tinggal & & \\
\hline & a. Tinggal sendiri & 4 & 7,27 \\
\hline & b. bersama saudara & 2 & 3,64 \\
\hline & c. bersama anak & 9 & 16,36 \\
\hline & $\begin{array}{ll}\text { d. } & \text { Bersama } \\
& \text { suami/isteri }\end{array}$ & 12 & 21,82 \\
\hline & $\begin{array}{ll}\text { e. } & \text { Bersama } \\
\text { Suami/istri dan } \\
\text { anak }\end{array}$ & 28 & 50,91 \\
\hline
\end{tabular}

Berdasarkan tabel 1 dapat diketahui bahwa persentase responden tertinggi pada distribusi usia 51-60 tahun yaitu sebanyak 29 orang $(52,73 \%)$, persentase tertinggi pada distribusi jenis kelamin yaitu perempuan sebanyak 34 orang $(61,82 \%)$, persentase tertinggi pada distribusi status perkawinan yaitu status menikah sebanyak 43 orang $(78,18 \%)$, persentase tertinggi pada distribusi pendidikan terbanyak pada tingkat SMP yaitu sebanyak 28 orang $(50,91 \%)$, dan persentase tertinggi pada distribusi tempat tinggal yaitu tinggal bersama suami/isteri dan anak sebanyak 28 orang $(50,91 \%)$.

b. Distribusi frekwensi dukungan keluarga

Tabel 2

Distribusi Frekuensi

Dukungankeluarga pada penderita hipertensi di wilayah kerja

Puskesmas Pancur Kabupaten

Lingga Tahun 2020

\begin{tabular}{|c|c|c|c|}
\hline \multirow[b]{2}{*}{ No } & \multicolumn{2}{|c|}{ Dukungan } & \multirow[b]{2}{*}{$\%$} \\
\hline & keluarga & $\mathrm{F}$ & \\
\hline 1 & Baik & 32 & 58,18 \\
\hline 2 & Sedang & 14 & 25,46 \\
\hline \multirow[t]{2}{*}{3} & Kurang & 9 & 16,36 \\
\hline & Total & 55 & 100 \\
\hline
\end{tabular}

Berdasarkan tabel 2 diketahui bahwa responden dengan kriteria dukungan keluarga tertinggi pada frekwensi baik yaitu sebanyak 32 orang $(58,18 \%)$.

c. distribusi frekwensi Kepatuhan diet hipertensi

Tabel 3

Distribusi Frekuensi Kepatuhan

Diet Pada Penderita Hipertensi Di

Wilayah Kerja Puskesmas Pancur

Kabupaten Lingga Tahun 2020 


\begin{tabular}{clcc}
\hline No & Kepatuhan diet & $\mathrm{f}$ & $\%$ \\
\hline 1 & Tinggi & 32 & 58,18 \\
2 & Menengah & 12 & 21,82 \\
3 & Rendah & 11 & 20,00 \\
& Total & 55 & 100 \\
\hline
\end{tabular}

Berdasarkan tabel 3 diketahui bahwa responden dengan kriteria kepatuhan diet tertinggi pada frekwensi kepetuhan diet tinggi yaitu sebanyak 32 orang $(58,18 \%)$.

\section{Analisa Bivariat}

Dengan menggunakan bantuan dari aplikasi komputer yaitu SPSS dilakukan uji Spearman rho dengan derajat kemaknaan $\alpha=0,05$, yaitu uji statistik untuk menguji 2

Tabel 4

Analisa Hubungan Dukungan

Keluarga Dengan Kepatuhan Diet Pada Penderita Hipertensi Di Wilayah Kerja Puskesmas Pancur Kabupaten Lingga Tahun 2020

\begin{tabular}{lcc}
\hline & \multicolumn{2}{c}{ Kepatuhan diet } \\
\hline $\begin{array}{l}\text { Dukungan } \\
\text { keluarga }\end{array}$ & $\mathrm{r}$ & 0,851 \\
\hline & $\mathrm{p}$ & 0,000 \\
\hline & $\mathrm{n}$ & 55 \\
\hline
\end{tabular}

Terdapat hubungan yang signifikan antara dukungan keluarga dengan kepatuhan diet hipertensi dengan derajat kemaknaan $\alpha=0,00$, diperoleh hasil $\mathrm{p}=0,000$ dimana $(\mathrm{p} \leq 0,05)$, dengan kekuatan $(\mathrm{r}=0,851)$ yaitu sangat kuat dan arah hubungan positif artinya koefisien korelasi adalah signifikan, self-management sehingga "H0 ditolak dan Ha diterima, yang berarti ada Hubungan Dukungan Keluarga Dengan Kepatuhan Diet Pada Penderita Hipertensi Di Wilayah
Kerja Puskesmas Pancur Kabupaten Lingga Tahun 2020".

\section{Analisa Univariat}

a. Distribusi Dukungan Keluarga

Dari hasil penelitian didapatkan hasil bahwa responden dengan dukungan keluarga baik sebanyak 32 orang $(58,18 \%)$, dukungan keluarga sedang sebanyak 14 orang $(25,46 \%)$ dan dukungan keluarga kurang sebanyak 9 orang (16,36\%). "Dukungan keluarga terbagi atas dukungan emosional, dukungan informasional, dukungan instrumental dan dukungan penghargaan". (Herlinah, 2013) mengatakan "pasien hipertensi yang mendapatkan dukungan informasi yang efektif berpeluang 6,7 kali memiliki perilaku baik dalam menjaga kesehatannya dibandingkan dengan pasien hipertensi yang tidak mendapatkan dukungan informasi dari keluarga". "Aspek-aspek dalam dukungan informasi adalah pemberian informasi, saran, dan nasehat yang diberikan oleh keluarga terhadap anggota keluarga lainnya" (Friedman, 2013).

Dari hasil penelitian peneliti berasumsi bahwa dukungan keluarga pada pasien hipertensi di wilayah kerja Puskesmas Pancur Kabupaten Lingga tergolong baik, hal ini dilihat dari hasil penelitian yang menunjukkan hasil kuesioner dukungan keluarga baik sebanyak 32 orang $\quad(58,18 \%)$ Peneliti menyimpulkan yang dihubungkan dengan pendapat para ahli bahwa dukungan keluarga yang terdiri dari empat domain yaitu dukungan dukungan emosional, dukungan informasional, dukungan instrumental dan dukungan penghargaan.sangat 
dibutuhkan oleh pasien hipertensi dalam menjalani upaya pengontrolan hipertensi yang dideritanya. Dukungan keluarga yang dimaksud dapat diterima dari anak, istri/suami, saudara dan orang tua. Dengan adanya dukungan keluarga yang baik akan membantu pasien untuk dapat mengontrol diet hipertensi.

b. Distribusi kepatuhan diet hipertensi

Dari hasil penelitian didapatkan hasil bahwa responden dengan Kriteria kepatuhan tinggi sebanyak 32 orang $(58,18 \%)$, kepatuhan menengah sebanyak 12 orang $(21,82 \%)$ dan kepatuhan rendah sebanyak 11 orang $(20 \%)$.

Penelitian (Hamid, 2013) hasil penelitian didapatkan bahwa dari 93 responden mayoritas yang patuh terhadap diet hipertensinya sebanyak 64 responden $(68,8 \%)$. Hal"ini sejalan dengan penelitian (Nita, 2018) bahwa dari 73 responden"mayoritas responden yang patuh melaksanakan diet hipertensinya sebanyak 47 responden $(64,4 \%)$ diperoleh nilai pvalue 0,016 terdapat hubungan yang signifikan antara movitasi diri terhadap kepatuhan melaksanakan diet pada penderita hipertensi. Dari hasil penelitian maka peneliti berasumsi bahwa Kepatuhan diet pada pasien hipertensi di wilayah kerja Puskesmas Pancur Kabupaten Lingga tergolong"baik, hal ini dilihat dari hasil penelitian yang menunjukkan"hasil kuesioner responden dengan Kriteria kepatuhan tinggi sebanyak 32 orang $(58,18 \%)$.

\section{Analisa bivariat}

Hubungan Dukungan Keluarga Dengan Kepatuhan Diet Pada Penderita Hipertensi Di Wilayah Kerja Puskesmas Pancur Kabupaten Lingga Tahun 2019.

Dari hasil penelitian dapat disimpulkan bahwa Terdapat hubungan yang signifikan antara dukungan keluarga dengan kepatuhan diet hipertensi dengan derajat kemaknaan $\alpha$ $=0,00$, diperoleh hasil $\mathrm{p}=0,000$ dimana $(\mathrm{p} \leq 0,05)$, dengan kekuatan $(\mathrm{r}=0,851)$ yaitu sangat kuat dan arah hubungan positif artinya koefisien korelasi adalah signifikan, ada Hubungan Dukungan Keluarga Dengan Kepatuhan Diet Pada Penderita Hipertensi Di Wilayah Kerja Puskesmas Pancur Kabupaten Lingga Tahun 2020. Menurut Asumsi peneliti hubungan dukungan keluarga dengan kepatuhan diet pada penderita hipertensi di wilayah Kerja Puskesmas Pancur Kabupaten Lingga dalam kategori baik dimana semakin tinggi dukungan keluarga maka akan semakin baik derajat kepatuhan pasie terhadap diet hipertensi. dukungan keluarga sangat penting diberikan kepada responden yang mengalami hipertensi, karena setiap sikap atau tindakan keluarga dapat mempengaruhi perilaku responden. Jika keluarga memberikan dukungan yang baik maka kepatuhan responden dalam melaksanakan diet hipertensi semakin tinggi. Sebaliknya, jika keluarga tidak memberikan dukungan keluarga maka kepatuhan responden dalam melaksakan diet hipertensi semakin rendah.

\section{Kesimpulan}

Responden dengan kriteria dukungan keluarga tertinggi pada frekwensi baik yaitu sebanyak 32 orang (58,18\%)

$\begin{array}{lcr}\text { Responden } & \text { dengan } & \text { kriteria } \\ \text { kepatuhan diet tertinggi } & \text { pada } \\ \text { frekwensi kepetuhan diet tinggi } & \text { yaitu } \\ \text { sebanyak 32 orang }(58,18 \%) & \\ \text { Terdapat hubungan } & \text { yang } \\ \text { signifikan antara dukungan keluarga } & \end{array}$


dengan kepatuhan diet hipertensi dengan derajat kemaknaan $\alpha=0,00$, diperoleh hasil $\mathrm{p}=0,000$ dimana $(\mathrm{p} \leq 0,05)$, dengan kekuatan $(\mathrm{r}=0,851)$ yaitu sangat kuat dan arah hubungan positif artinya koefisien korelasi adalah signifikan, yang berarti"ada Hubungan Dukungan Keluarga Dengan Kepatuhan Diet Penderita Hipertensi Di Wilayah Kerja Puskesmas Pancur Kabupaten’Lingga Tahun 2020.

\section{BIBLIOGRAFI}

Agrina. (2013). "Upaya pencegahan dan penanggulangan hipertensi melalui pola makan sangat penting bagi penderita hipertensi. Pengaturan diet pada penderitahipertensi dan keteraturan pemeriksaan tekanan darah akan berhasil apabila pasien patuh.

Bertalina, B., \& Muliani, M. (2016). Hubungan pola makan, asupan makanan dan obesitas sentral dengan hipertensi di Puskesmas Rajabasa Indah Bandar Lampung. Jurnal Kesehatan, 7(1), 34-45.

Friedman. (2013). “Aspek-aspek dalam dukungan informasi adalah pemberian informasi, saran, dan nasehat yang diberikan oleh keluarga terhadap anggota keluarga lainnya".

Hamid, S. . (2013). hasil penelitian didapatkan bahwa dari 93 responden mayoritas yang patuh terhadap diet hipertensinya sebanyak 64 responden $(68,8 \%)$.

Herlinah. (2013). mengatakan "pasien hipertensi yang mendapatkan dukungan informasi yang efektif berpeluang 6,7 kali memiliki perilaku baik dalam menjaga kesehatannya dibandingkan dengan pasien hipertensi yang tidak mendapatkan dukungan informasi dari keluarga”.
Huda, B., Kumala, S., \& Hasan, D. (2020). Analisis Ketersediaan Obat Antihipertensi Dan Pengaruhnya Terhadap Pengobatan Pasien Hipertensi Di Puskesmas Kota Bandar Lampung. Syntax Literate; Jurnal Ilmiah Indonesia, 5(6), 34-49.

Lindner, Menzies, Kelly,Taylor, dan S. (2013). "pemberian intervensi merupakan faktor penting dalam perubahan sikap kepatuhan dalam pengobatan penyakit kronik seperti perubahan sikap dalam kepatuhan minum obat, kepatuhan aktivitas sehari-hari dan kepatuhan melaksanakan diet".

Muchid, A., Umar, F., Chusun, M., Wurjati, R., \& Purnama, N. R. (2006). Pharmaceutical care untuk penyakit hipertensi. Direktorat Bina Farmasi Komunitas Dan Klinik Ditjen Bina Kefarmasian Dan Alat Kedokteran Departemen Kesehatan.

Nita. (2018). bahwa dari 73 responden"mayoritas responden yang patuh melaksanakan diet hipertensinya sebanyak 47 responden (64,4\%) diperoleh nilai pvalue 0,016 terdapat hubungan yang signifikan antara movitasi diri terhadap kepatuhan melaksanakan diet pada penderita hi.

Rahmayani, S. T. (2019). Faktor-Faktor Risiko Kejadian Hipertensi Primer pada Usia 20-55 Tahun di Poliklinik Penyakit Dalam RSUD 45 Kuningan. Syntax, 1(4).

Rosyid \& Effendy. (2016). menunjukkan bahwa "rendahnya angka kepatuhan terhadap diet rendah garam membuat meningkatnya angka kejadian hipertensi".

Runtukahu, dkk. (2015). "peningkatan tekanan darah seseorang di atas 120/80mmHg yang merupakan salah satu penyebab utama penyakit jantung, stroke dan gagal ginjal". 
Soenarta. (2015). Keberhasilan pengobatan hipertensi salah satunya dipengaruhi oleh kepatuhan melaksanakan diet. Melaksanakan pola hidup sehat telah banyak terbukti dapat menurunkan tekanan darah serta dapat mencegah terjadinya penyakit kardiovaskuler.

Sustrani. (2015). "Dukungan keluarga yang diberikan pada penderita hipertensi meliputi dukungan informasi, finansial, dukungan emosional dan dukungan penilaian atau penghargaan".

Copyright holder:

Nilam Sari, Mira Agusthia, Rachmawaty M Noer (2020)

First publication right:

Jurnal Health Sains

This article is licensed under:

(c) () () 